\title{
Scale-depend effectiveness of on-field vs. off-field agri-environmental measures for biodiversity
}

\author{
Péter Batáry ${ }^{1}$ and Teja Tscharntke ${ }^{2}$ \\ ${ }^{1}$ Center for Ecological Research and Forestry Applications \\ ${ }^{2}$ University of Goettingen
}

February 2, 2021

\begin{abstract}
Measuring the effectiveness of agri-environment schemes depends on scheme type, taxon and landscape. Here we show how spatial scale, i.e. studied transect, field or farm level, and controlling for yield loss, can drastically change the evaluation of biodiversity benefits of on-field (organic farming) vs. off-field (flower strips) schemes. Transects may lead to misleading evaluations, because flower strips, covering only $5 \%$ of conventional fields, support less bees than large organic fields; but if their $20 \%$ yield loss is considered to compare identical yield levels, 80 ha conventional plus 20 ha flower strip farming promotes more bees than 100 ha organic farming.
\end{abstract}

Scale-depend effectiveness of on-field vs. off-field agri-environmental measures for biodiversity Péter Batáry ${ }^{1,{ }^{*}}$ and Teja Tscharntke ${ }^{2}$

${ }^{1}$ Lendület Landscape and Conservation Ecology, Institute of Ecology and Botany, Centre for Ecological Research, Alkotmány u. 2-4, 2163 Vácrátót, Hungary. E-mail: pbatary@gmail.com

${ }^{2}$ Agroecology, University of Goettingen, Grisebachstr. 6, 37077 Göttingen, Germany. E-mail:

ttschar@gwdg.de

*Correspondence: Tel.: + 36-28-360122. E-mail: pbatary@gmail.com.

ORCID ID: 0000-0002-1017-6996 (P. Batáry), 0000-0002-4482-3178 (T. Tscharntke)

Statement of authorship: P.B., and T.T. conceived and developed the study; P.B. collected and analysed the data; and P.B. wrote the paper with substantial input from T.T.

Data accessibility statement: The data that support the findings of this study will be made available in the repository Zenodo upon the acceptance of the manuscript.

Short running title: Effectiveness of agri-environment schemes

Keywords: Agri-environment scheme, bees, farm scale, field scale, flower strip, landscape structure, organic farming, pollinators, yield loss, wheat.

Type of article: Viewpoints

Abstract word count: 100 Main text word count: 1503

Number of references: 25 Number of figures: 1

Abstract 
Measuring the effectiveness of agri-environment schemes depends on scheme type, taxon and landscape. Here we show how spatial scale, i.e. studied transect, field or farm level, and controlling for yield loss, can drastically change the evaluation of biodiversity benefits of on-field (organic farming) vs. off-field (flower strips) schemes. Transects may lead to misleading evaluations, because flower strips, covering only $5 \%$ of conventional fields, support less bees than large organic fields; but if their $20 \%$ yield loss is considered to compare identical yield levels, 80 ha conventional plus 20 ha flower strip farming promotes more bees than 100 ha organic farming.

There is a decades-long discussion on how landscape may be designed delivering high agricultural productivity and biodiversity conservation alike (Zhang et al. 2007; Landis 2017). To address these challenges, a variety of agri-environment schemes (AES) have been introduced (Batáry et al. 2015). The AES exhibit a positive effect on species richness and abundance of farmland biota, but these effects depend on taxonomic group, landscape structure and ecological contrast between the treated and the control site (Batáry et al.2015; Marja et al. 2019). Recently, (Batáry et al. 2015) reviewed the broad range of European AES with a meta-analysis and compared their relative contributions to biodiversity conservation. AES approaches can focus on nonproductive areas, such as field boundaries and wildflower strips (off-field practices (Garibaldi et al.2014)), or productive areas, such as arable crops or grasslands (on-field practices). Schemes promoting off-field areas include hedgerows (often for bird conservation (Batáry et al. 2012)), sown or naturally regenerated field margins (often flower strips for pollinators (Pywell et al. 2012)) or simply taking land out of production (e.g. abandoned land for great bustard conservation in Hungary (Kovács-Hostyánszki et al. 2011)). In contrast, on-field practices support environmentally sensitive approaches to the management of land that is used to grow crops or feed livestock. For example, they might reduce or prohibit the use of agrochemicals or confine management such as mowing grassland within specified points in time. The most widespread on-field scheme is organic farming (Reganold \& Wachter 2016; Seufert \& Ramankutty 2017). Batáry et al. (2015a) found that off-field schemes were much more effective at enhancing species richness than on-field schemes. The conversion of crop monocultures to semi-natural habitat results in a much larger increase in resource availability (i.e. creates a larger ecological contrast to the untreated control) for a wider range of species than on-field schemes, such as reducing stocking rates or restricting fertilizer and pesticide application in organic farming (Marja et al. 2019). Furthermore, schemes promoting the establishment of wildflower strips might be better targeted to the conservation of a given species group than on-field schemes, because they often specifically address a resource that is limiting population growth or size, e.g. floral resources for flower visiting insects (Warzecha et al. 2018).

However, the meta-analysis by Batáry et al. (2015a) has limitations in the comparison of off- vs. on-field practices, as it combines very different studies, which refer to biodiversity gains at very different spatial scales. For example, insect and plant surveys cover typically only a minor part of a study field (e.g. the field margin) without considering upscaling the effect size to the whole field or farm. Further, biodiversity-yield trade-offs have not been considered. Gabriel et al. (2013) showed in a large scale UK study that arthropod diversity did not differ between organic and conventional cereal fields when controlling for the more than $50 \%$ yield loss in organic farming. Here, we focus on different spatial scales of two most popular AESs (Batáry et al. 2015), namely organic farming as on-field measure and planted flower strips as off-field measure, leading to contrasting assessments of their biodiversity value.

In general, organic farming is applied at farm scale, and organic farmers do not apply for flowering strip (FS) schemes. Hence, FS as an AES is typically used by conventional farmers. FS are usually sown with seed mixtures of wild flowers and/or flowering crop species on arable land along field boundaries (Marshall \& Moonen 2002; Warzecha et al. 2018). The width, the species mixtures and the management of the strips vary between countries and even between states. FS are most often targeted for insect conservation, especially favouring flower visitors to ensure crop pollination and natural enemies contributing to biological pest control (Wratten et al. 2012; Blaauw \& Isaacs 2014; Tschumi et al. 2015). Haaland et al. (2011) found in their review that sown wild FS support higher insect abundances and diversity than cropped habitats.

In this study, we illustrate four different scenarios of scale-dependency of these agri-environment schemes by 
using wild bee data of three types of surveys (organic wheat field, conventional wheat field and conventional wheat fields with FS) from ten landscapes replicated in two years (methods: Supplement 1). We investigated, whether the effectiveness of the two AES (relative to the control, i.e. conventional fields) depends on the spatial scale considered. We supposed that scaling up the transect level data to field or farm level, by considering their larger contribution due to their larger area, and controlling for yield loss, might significantly change the whole picture.

Tuck et al. (2014) found in their meta-analysis that organic management supports $30 \%$ higher species richness per 1 ha field than conventional management. Flower strips adjacent to conventional fields are often found to be even more species rich than organic fields without such strips. Batáry et al. (2015) quantified this in their meta-analysis in that off-field practices (often flower strips) were more effective measures in maintaining or restoring biodiversity than measures on productive areas, such as organic farming on arable land or grassland; effect size of off-field practices was about two times high than that of on-field practices. In this scenario, comparisons consider the transect level, i.e. sampling of pollinator data at the transect level of organic vs. conventional vs. FS (adjacent to conventional fields) (Geppert et al. 2020), exhibiting an eight times higher effectiveness of FS than organic management (Fig. 1a).

The second scenario focuses on the field level, considering the area share of sown flowers in case of FS fields (Fig. 1b). When FS occupy $15 \%$ of a conventional field, which was the situation in our study (Geppert et al. 2020), the effectiveness of conventional management with FS was still $43 \%$ higher than the effectiveness of organic management (compared to conventional fields without FS). Hence, the difference at field level is much less expressed than in the transect scenario.

In the third scenario, we further scaled up pollinator abundance data to farm level with farm size of 100 ha. In case of conventional farming with FS, this extrapolation of field to a 100 ha farm level considered $5 \%$ area taken out for FS. We took 5\% FS, as it corresponds to the minimum area of the greening measure of the Common Agricultural Policy (Zinngrebe et al. 2017). We found that 100 ha organic farming, which is usually characterized by a much higher cover of flowering weeds than conventional fields (Batáry et al. 2013), was about twice more effective than 100 ha conventional farming including FS in supporting pollinator abundance. This is because organic management promotes bee abundance with a 20 times larger area than the small area (5 ha) of flower strips. Holzschuh et al. (2008) showed that increasing the area with organic farms per landscape from $5 \%$ to $50 \%$ triples the number of bee species on surrounding fallows.

The last scenario controls for yield loss in organic compared to conventional farming (Gabriel et al. 2013). As productivity of organic farms is, on average, 20\% lower worldwide (Seufert \& Ramankutty 2017), 100 ha organically managed farm may be compared with 80 ha conventional farm with 20 ha flower strips, thereby producing equal crop yield. In this situation, the same yield per 100 ha farm is the target, and we found that organic farming supported about $40 \%$ fewer pollinators due to the large area of flowering strips/fields allowed in conventional farming. When organic yield is even halved (as in case of cereals (Gabriel et al. 2013; Batáry et al. 2017)), the difference can be even much higher. Finally, one might consider further scenarios that we could not test with our data. For example, if organic farmers manage their farms with higher crop diversity and longer crop rotations than conventional farmers, biodiversity might further increase (Sirami et al. 2019).

A plethora of studies addresses the ecological effectiveness of different agri-environment schemes with nearly all of them focusing exclusively on the transect level (Batáry et al. 2015), whereas upscaling to higher spatial scale (field or farm level) is rare (Batáryet al. 2017). Although small-scale off-field measure can have a very positive biodiversity outcome at that scale, such as in case of flower strips, upscaling to field and farm level can reveal that the biodiversity benefit of FS is on par or even lower than that of on-field measures such as organic farming (Geppert et al. 2020). Focusing studies on the transect scale can give misleading results, as FS make up typically only ca. $5 \%$ of a conventional farm, enhancing less bees than a same sized organic farm. This, can be turned around again, when we control for yield losses from organic farming (Chave 2013). As yield in organic farming is on average $20 \%$ lower, 100 ha organic farm has the same productivity as 80 ha conventional farm with 20 ha flower strips, which supports much higher biodiversity than organic 
farming. In conclusion, considering various scales in the evaluation of AES measures is necessary in order to get a balanced understanding of their ecological and also economic effects for further development of their effectiveness.

\section{Acknowledgements}

This paper is a result of the project, "Biodiversity and associated ecosystem services in small-vs. largescale agriculture" (DFG BA 4438/2-1). We thank Bettina Donkó, Rita Földesi, Marian Mendoza García, Costanza Geppert, Jacob Rosenthal, Carolina Steffen and Sinja Zieger for assistance with the field work, Zsolt Józan for identification of bees and Jacqueline Loos for discussion on this study. PB was supported by the Hungarian National Research, Development and Innovation Office (NKFIH KKP 133839).

\section{References}

Batáry, P., Dicks, L. V., Kleijn, D. \& Sutherland, W.J. (2015). The role of agri-environment schemes in conservation and environmental management. Conserv. Biol. , 29, 1006-1016.

Batáry, P., Gallé, R., Riesch, F., Fischer, C., Dormann, C.F., Mußhoff, O., et al. (2017). The former Iron Curtain still drives biodiversity-profit trade-offs in German agriculture. Nat. Ecol. Evol., 1, 1279-1284.

Batáry, P., Kovács-Hostyánszki, A., Fischer, C., Tscharntke, T. \& Holzschuh, A. (2012). Contrasting effect of isolation of hedges from forests on farmland vs. woodland birds. Community Ecol. , 13, 155-161.

Batáry, P., Sutcliffe, L., Dormann, C.F. \& Tscharntke, T. (2013). Organic farming favours insect-pollinated over non-insect pollinated forbs in meadows and wheat fields. PLoS One, 8, e54818.

Blaauw, B.R. \& Isaacs, R. (2014). Flower plantings increase wild bee abundance and the pollination services provided to a pollination-dependent crop. J. Appl. Ecol. , 51, 890-898.

Chave, J. (2013). The problem of pattern and scale in ecology: What have we learned in 20 years? Ecol. Lett. , 16, 4-16.

Gabriel, D., Sait, S.M., Kunin, W.E. \& Benton, T.G. (2013). Food production vs. biodiversity: comparing organic and conventional agriculture. J. Appl. Ecol. , 50, 355-364.

Garibaldi, L.A., Carvalheiro, L.G., Leonhardt, S.D., Aizen, M.A., Blaauw, B.R., Isaacs, R., et al. (2014). From research to action: enhancing crop yield through wild pollinators. Front. Ecol. Environ., 12, 439-447.

Geppert, C., Hass, A., Földesi, R., Donkó, B., Akter, A., Tscharntke, T., et al. (2020). Agri-environment schemes enhance pollinator richness and abundance but bumblebee reproduction depends on field size.J. Appl. Ecol. , 57, 1818-1828.

Haaland, C., Naisbit, R.E. \& Bersier, L.F. (2011). Sown wildflower strips for insect conservation: A review. Insect Conserv. Divers. , 4, 60-80.

Holzschuh, A., Steffan-Dewenter, I. \& Tscharntke, T. (2008). Agricultural landscapes with organic crops support higher pollinator diversity. Oikos , 117, 354-361.

Kovács-Hostyánszki, A., Korösi, Á., Orci, K.M., Batáry, P. \& Báldi, A. (2011). Set-aside promotes insect and plant diversity in a Central European country. Agric. Ecosyst. Environ., 141, 296-301.

Landis, D.A. (2017). Designing agricultural landscapes for biodiversity-based ecosystem services. Basic Appl. Ecol. , 18, 1-12.

Marja, R., Kleijn, D., Tscharntke, T., Klein, A.M., Frank, T. \& Batáry, P. (2019). Effectiveness of agrienvironmental management on pollinators is moderated more by ecological contrast than by landscape structure or land-use intensity. Ecol. Lett. , 22, 1493-1500.

Marshall, E.J.P. \& Moonen, A.C. (2002). Field margins in northern Europe: their functions and interactions with agriculture. Agric. Ecosyst. Environ., 89, 5-21. 
Pywell, R.F., Heard, M.S., Bradbury, R.B., Hinsley, S., Nowakowski, M., Walker, K.J., et al. (2012). Wildlifefriendly farming benefits rare birds, bees and plants. Biol. Lett. , 8, 772-5.

Reganold, J.P. \& Wachter, J.M. (2016). Organic agriculture in the twenty-first century. Nat. Plants , 2, 1-8.

Seufert, V. \& Ramankutty, N. (2017). Many shades of gray - the context-dependent performance of organic agriculture. Sci. Adv., 3, e1602638.

Sirami, C., Gross, N., Baillod, A.B., Bertrand, C., Carrié, R., Hass, A., et al. (2019). Increasing crop heterogeneity enhances multitrophic diversity across agricultural regions. Proc. Natl. Acad. Sci. U. S. A., 116, $16442-16447$.

Tschumi, M., Albrecht, M., Entling, M.H. \& Jacot, K. (2015). High effectiveness of tailored flower strips in reducing pests and crop plant damage. Proc. R. Soc. B Biol. Sci. , 282, 189-196.

Tuck, S.L., Winqvist, C., Mota, F., Ahnström, J., Turnbull, L.A. \& Bengtsson, J. (2014). Land-use intensity and the effects of organic farming on biodiversity: a hierarchical meta-analysis. J. Appl. Ecol. , 51, 746-755.

Warzecha, D., Diekötter, T., Wolters, V. \& Jauker, F. (2018). Attractiveness of wildflower mixtures for wild bees and hoverflies depends on some key plant species. Insect Conserv. Divers. , 11, 32-41.

Wratten, S.D., Gillespie, M., Decourtye, A., Mader, E. \& Desneux, N. (2012). Pollinator habitat enhancement: benefits to other ecosystem services. Agric. Ecosyst. Environ. , 159, 112-122.

Zhang, W., Ricketts, T.H., Kremen, C., Carney, K. \& Swinton, S.M. (2007). Ecosystem services and disservices to agriculture. Ecol. Econ. , 64, 253-260.

Zinngrebe, Y., Pe'er, G., Schueler, S., Schmitt, J., Schmidt, J. \& Lakner, S. (2017). The EU's ecological focus areas - how experts explain farmers' choices in Germany. Land Use Policy , 65, 93-108.

\section{Hosted file}

image1.emf available at https://authorea.com/users/393267/articles/506921-scale-dependeffectiveness-of-on-field-vs-off-field-agri-environmental-measures-for-biodiversity

Figure 1. Bee abundance sampled at transect level in organic field, conventional control field and flower strip, and their upscaling to field and farm scales with different scenarios. Scenario 1: At transect level, the effectiveness of flower strip (FS) scheme (EF2: compared to conventional field) was eight times higher than the effectiveness of organic management (EF1: compared to conventional field). Scenario 2: At field level, when FSs occupied $15 \%$ of a conventional field, the effectiveness of conventional management with FS (EF3) was $43 \%$ higher than the effectiveness of organic management (EF4). Scenario 3: Based on the same farm area (100 ha), organic farming was more effective (EF5) than conventional farming containing $5 \%$ FS and 95\% conventional fields (EF6). Scenario 4: Based on the same farm area (100 ha) and same yield loss, i.e. conventional farming with ca. $20 \%$ FS (EF8) was more efficient than organic farming (EF7) $(\mathrm{n}=60$ transects and fields; $\mathrm{n}=40$ farms). Error bars represent standard error of mean. Significance levels: ${ }^{* * *} \mathrm{P}<0.001$. Abundance closely correlated with species numbers in our dataset (Pearson's $\mathrm{r}=0.80, \mathrm{P}<0.001$ ). 